\title{
Effects of neonatal medroxyprogesterone acetate on post- natal sexual differentiation of female rats
}

\author{
Lynda I. A. Birke, Christiane Holzhausen, S. Murphy and Dawn Sadler
}

Brain Research Group, Biology Department, The Open University, Milton Keynes $M K 76 A A, U . K$.

\begin{abstract}
Summary. Medroxyprogesterone acetate (MPA), $5 \mu \mathrm{g} / \mathrm{g}$ body wt, was given to lactating female rats 1 day after parturition. Group 1 females suckled 10-12 young, with equal numbers of males and females, while Group 2 females each suckled 10 female young. The young were weaned at 21 days of age. Exposure to MPA advanced the day of vaginal opening by 1 day, and increased anogenital distance in Group 2 young. At autopsy between 80 and 100 days of age, the clitoris of Group 2 females was significantly greater than in controls, and ovarian and adrenal weights were reduced.
\end{abstract}

\section{Introduction}

The effects of androgens and oestrogens on mechanisms of sexual differentiation in mammals have been much studied: by contrast, little is known about any potential involvement of progestagens. Indeed, until recently, much of the available literature has tended to assume that progestagens have little to do with sexual differentiation, except possibly providing some protection for the hypothalamic-hypophysial-gonadal axis against the effects of androgens (as reported, e.g., for progesterone: Kincl \& Maqueo, 1965). However, progestational steroids do, in fact, influence mechanisms of sexual differentiation. This evidence is of two types. First, the existence of specific progestagen receptors has been demonstrated in various tissues, such as the immature rat uterus (Philibert \& Raynaud, 1973), guinea-pig fetal uterus and ovary (Pasqualini \& Nguyen, 1980) and neonatal rat brain (see MacLusky \& McEwan, 1980; Kato \& Onouchi, 1981), suggesting that perinatal progestagens may be more actively involved in physiological differentiation than previously thought.

A second source of evidence for progestagen involvement in sexual differentiation comes from studies of long-term behavioural consequences of progestagen exposure. In rodents, these include maze learning (Hull, Franz, Snyder \& Nishita, 1980), adult sexual behaviour (Hull, 1981) and juvenile play behaviour (Birke \& Sadler, 1983).

Potential sources of progestagens during early mammalian development include progestagens present in the maternal and placental circulation, as well as fetal gonads and adrenals. After birth, the chief sources are the infant gonads and adrenals and, in the rat at least, there is evidence that neonatal males and females differ in quantities of circulating progestagens (see Shapiro, Goldman, Bongiovan \& Marino, 1976; C. Holzhausen, unpublished observations), a difference which might contribute to post-natal sexual differentiation. In addition, the maternal organism might continue to supply progestagens to the young via milk. It is known that steroids do pass into the lipid fraction of milk; their subsequent effects will then depend, in part, upon the extent to which they are orally active. Oestrogens (Hain, 1935) and progestagens (Hull, 1981; Holzhausen, 1982; Holzhausen, Murphy \& Birke, 1984) have been shown to affect sexual differentiation in rats after ingestion in milk. 
In this paper, we report some effects of neonatal exposure of rat pups to the long-acting progestagen, medroxyprogesterone acetate (MPA), obtained via maternal milk. Medroxyprogesterone acetate is clinically used for its antiandrogenic properties, and is used in the treatment of several disorders (Mathews, Abrams \& Morishima, 1970; Money, 1970; Berlin \& Meinecke, 1981). On this basis, it might be expected that, if MPA were to affect sexual differentiation at all, it would have an antiandrogenic effect. There have, however, been few studies of MPA during the critical period for sexual differentiation, although one early study exposed rat fetuses to the hormone via placental circulation, and reported a masculinizing effect on the external genitalia of female fetuses (Revesz, Chappel \& Gaudry, 1960). In rats, MPA has been shown to enter milk and then to enter the gut in an unmetabolized form (Holzhausen, 1982). When administered to sucking young, it has also been shown to effect a delay in the day of vaginal opening (Satayasthit, Tankeyoon \& Chaudhury, 1976).

\section{Materials and Methods}

The rats used were Wistar-derived animals (CFHB) bred in the Open University animal house. The animals were time mated and housed in groups of 4-6 until Day 18 of pregnancy, when they were removed and housed singly. Food and water were available ad libitum. The rats in Group 1 were housed on a reversed-light schedule (lights on from $21: 00$ to $09: 00 \mathrm{~h}$ ), while those in Group 2 were on a normal light schedule (lights 09:00-21:00 h).

Treatment. As soon as litters were born, they were allocated at random to matched pairs. All the young born to each pair of dams were pooled, and litter size and sex ratio were adjusted for Group 1, using a split litter design, so that, as far as possible, each female received an equal number of male and female young. Litter size was kept at 10-12 and extra young were culled. In Group 2 the mothers were similarly treated as matched pairs, but only female offspring were returned from the pool to give each mother 10 young. If the pool contained insufficient numbers of females, additional young of the same age were added from others litters before allocation to the matched dams. For both groups, one dam in each matched pair then received a subcutaneous injection of MPA on the day after parturition (Day 2), at a dose of $5 \mu \mathrm{g} / \mathrm{g}$ bodyweight. The hormone was given in a suspension of $0.9 \%(\mathrm{w} / \mathrm{v}) \mathrm{NaCl}(0 \cdot 1 \mathrm{ml})$. The matched control dam was similarly injected with $0 \cdot 1$ $\mathrm{ml}$ saline alone. Thereafter, all young remained undisturbed with the mother, apart from taking the measurements outlined below, until Day 21, when they were weaned and housed in single-sex sibling groups of 4-8 animals per cage.

Measurements. On the day of birth, after re-allocation, similarly matched pairs of young were weighed and the anogenital distance of each neonate was recorded. Similar measurements were taken subsequently every 5 days, until 50 days of age. From Day 30 onwards, female young were inspected for the day of vaginal opening, indicating puberty. All the remaining animals in Group 2 were killed between 80 and 100 days of age, when in pro-oestrus, as determined by vaginal smear patterns, and the adrenals, ovaries and uteri were excised and weighed. In addition, the clitoral length of these females was measured post mortem. Measurements of clitoral length or anogenital distance were taken using Vernier calipers, with the animal held horizontally with its hindlegs stretched out. Although this method holds the animal fairly steady during measurement of anogenital distance, there is inevitably a risk of error due to movement. However, all measurements of clitoral length were taken as soon as the animals were killed, with the animal fully stretched out.

Medroxyprogesterone acetate (MPA), 17 $\alpha$-hydroxy-6- $\alpha$-methyl-progesterone acetate, was purchased from Sigma (U.K.).

\section{Results}

There were no differences (two-way analysis of variance) in body weight of the control and MPAexposed young: the mean \pm s.d. : respective body weights $(\mathrm{g})$ were $11 \cdot 2 \pm 2 \cdot 0$ and $11 \cdot 33 \pm 2 \cdot 2$ at 5 


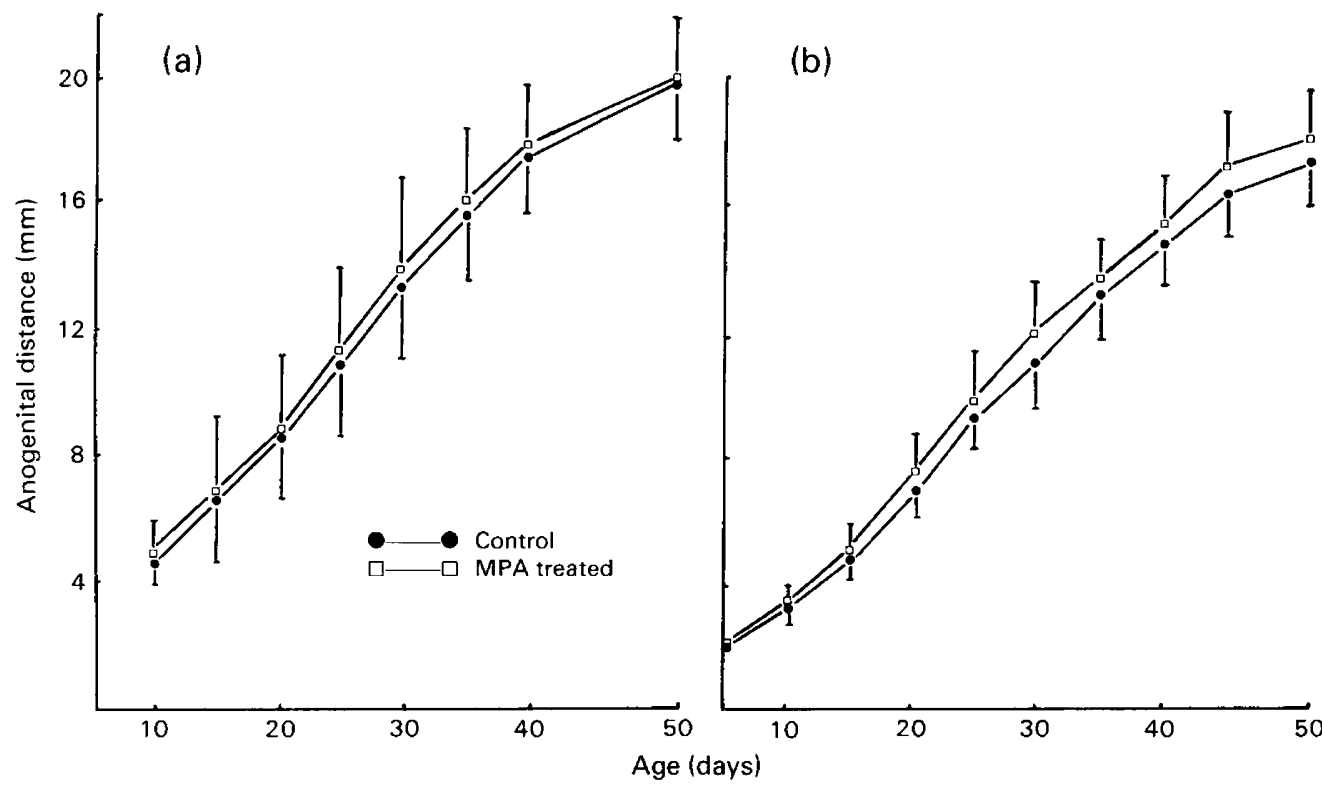

Text-fig. 1. The effect of neonatal MPA exposure via milk on mean \pm s.d. anogenital distance at various ages in (a) Group 1 females $(\mathrm{N}=39-56)$ and (b) Group 2 females $(\mathrm{N}=32-71)$.

days after birth; $18 \cdot 2 \pm 4.3$ and $19 \cdot 3 \pm 4.8$ at 10 days $; 27.5 \pm 4.5$ and $26.9 \pm 5.0$ at 15 days; $37.6 \pm$ 7.7 and $36.1 \pm 8.7$ at 20 days; $54.8 \pm 7.9$ and $52.4 \pm 8.6$ at 25 days; $73.9 \pm 12.8$ and $74.9 \pm 11.3$ at 30 days; $95.6 \pm 15 \cdot 4$ and $96 \cdot 1 \pm 11 \cdot 7$ at 35 days; $125.8 \pm 15 \cdot 1$ and $126.4 \pm 12.0$ at 40 days; and $154 \cdot 8 \pm 21 \cdot 5$ and $154 \cdot 1 \pm 12 \cdot 1$ at 50 days.

The results for anogenital distance are shown in Text-fig. 1. Analysis of variance showed nonuniformity (for controls, F values 38-82.6, d.f. 92-101; MPA-exposed, F values $20-72 \cdot 5$, d.f. = 111). The trend for increased anogenital distance in MPA-exposed females was significant (repeated $t$ tests, $P<0.05$ ) only for Group 2 animals after 15 days of age. Clitoral length, measured post mortem in Group 2 females, was significantly greater in the MPA-exposed young (Table 1). Adrenal and ovarian weights were also affected (Table 1). Frequency histograms for these data are shown in Text-fig. 2.

In the control young of Groups 1 and 2 vaginal opening occurred at $38.5 \pm 2.46$ days (mean \pm s.d., $\mathbf{N}=51)$; in MPA-exposed females the value was $37 \cdot 1 \pm 2.20(\mathrm{~N}=52)(P<0 \cdot 01, t$ test $)$.

\section{Discussion}

The results presented here indicate that oral exposure to MPA via maternal milk during the first few days post partum exerts some effect on reproductive tract development in the female rat: in MPA-exposed females the external genitalia tend to be enlarged, as shown particularly by measurements of clitoral length, ovarian and adrenal weights are smaller, and the onset of puberty (as measured by day of vaginal opening) is advanced by 1 day. The finding that neonatal progestagen exposure does not significantly alter body weight is in accord with findings obtained in other studies (Logothetopoulos, Sharma \& Kraicer, 1961; Satayasthit et al., 1976; Tapanainen, 1979; Hull et al., 1980).

The effects of MPA on genital morphology suggest androgenic actions, at least on peripheral tissues, although the mechanism is unclear. MPA is used, clinically, for its anti-androgenic effects (see 'Introduction'). The anti-androgenicity of progesterone appears to be due to competition for 


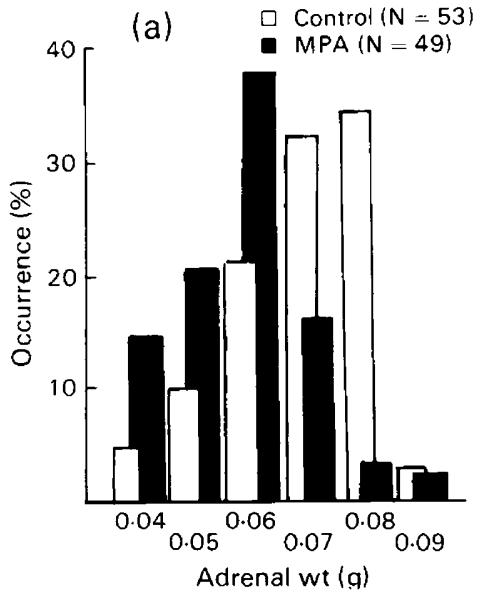

(b)

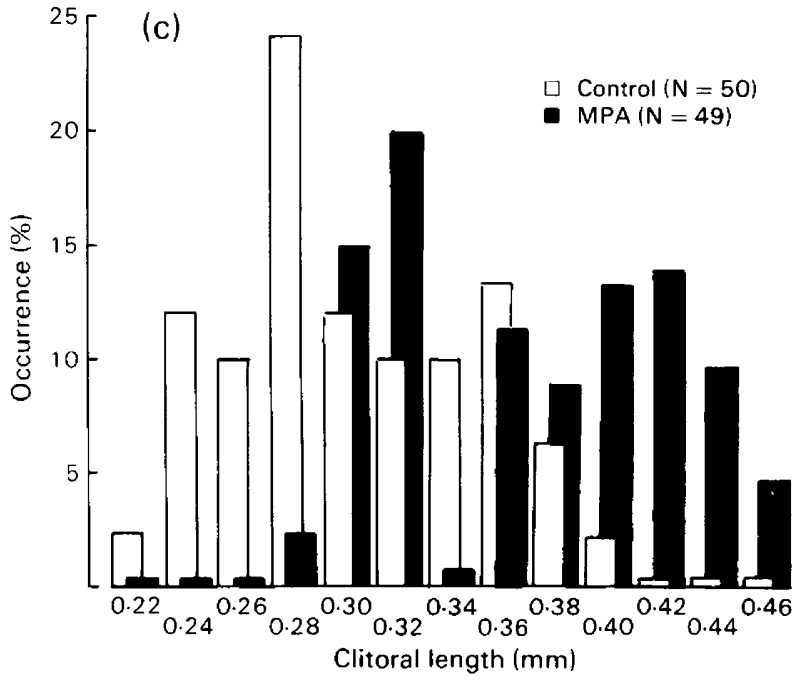

Text-fig. 2. The effect on neonatal MPA exposure on (a) adrenal weights, (b) ovarian weights and (c) clitoral size in adult female rats (Group 2).

Table 1. The effects in adult females rats (Group 2) of neonatal exposure to medroxyprogesterone acetate

\begin{tabular}{lcccccc}
\hline & \multicolumn{2}{c}{ Control females } & & \multicolumn{2}{c}{ MPA exposed } & \\
\cline { 2 - 3 } & No. & Mean \pm s.d. & & No. & Mean \pm s.d. & Significance \\
\hline Clitoral length $(\mathrm{mm})$ & 50 & $0.314 \pm 0.045$ & & 46 & $0.379 \pm 0.065$ & $P<0.001$ \\
Adrenal weight $(\mathrm{g})$ & 53 & $0.071 \pm 0.012$ & & 49 & $0.060 \pm 0.011$ & $P<0.001$ \\
Ovarian weight $(\mathrm{g})$ & 51 & $0.141 \pm 0.034$ & & 50 & $0.122 \pm 0.031$ & $P<0.01$ \\
Uterine weight $(\mathrm{g})$ & 40 & $0.827 \pm 0.274$ & & 41 & $0.888 \pm 0.199$ & NS \\
\hline
\end{tabular}

$5 \alpha$-reductase, the enzyme involved in the reduction of testosterone to its metabolite, $5 \alpha-$ dihydrotestosterone (Massa \& Martini, 1971). However, since it is principally $5 \alpha$-dihydrotestosterone that stimulates masculine development of the external genitalia (Schultz \& Wilson, 1974), it is 
not clear why genital enlargement should follow MPA administration. Neonatal MPA and progesterone appear to exert demasculinizing effects on behavioural development (Hull, 1981; Birke \& Sadler, 1983). However, MPA and progesterone can have apparently 'androgenic' effects on hypothalamic responsiveness when given neonatally. Chronic progesterone exposure during the first 3 weeks of life can induce ovulatory failure in rats (Bukovsky, Presl \& Krabec, 1979). Similarly, neonatal exposure to MPA has been shown to depress the amplitude of the LH surge (Holzhausen, 1982; Holzhausen et al., 1984), and in an apparently dose-dependent fashion.

The slight reduction in adrenal weight after exposure to MPA via the milk in neonatal life seems to be even more pronounced when MPA or progesterone are injected directly (Logothetopoulos $e t$ al., 1961; Tapanainen, 1979). The effect could be on adrenocortical function, possibly by means of an effect on pituitary ACTH synthesis (see Mathews et al., 1970).

The slight, but significant advancement of the time of vaginal opening in the present study is in direct contrast to the findings of Satayasthit et al. (1976), who reported a 1 day delay in vaginal opening of rats exposed to MPA via milk. This contradiction may be due to the use of a different strain of rat, or a slightly different methodology. For example, in the study by Satayasthit et al. (1976) the mothers were injected on Day 3 after parturition, whereas our rats were injected on Day 2.

In conclusion, these findings suggest that medroxyprogesterone acetate can produce a slight but significant masculinizing effect on some features of the development of young female rats. Although MPA appears to have been metabolized by the time that it has entered the peripheral tissues of the young (Holzhausen, 1982), the metabolite(s) are evidently still biologically active.

\section{References}

Berlin, F.S. \& Meinecke, C.F. (1981) Treatment of sex offenders with anti-androgenic medication: conceptualization, review of treatment modalities, and preliminary findings. Am. J. Psychiat. 138, 601-607.

Birke, L.I.A. \& Sadler, D. (1983) Progestin-induced changes in play behaviour of the prepubertal rat. Physiol. Behav. 30, 341-347.

Bukovsky, A., Presl, J. \& Krabec, Z. (1979) Effects of postnatal progesterone treatment on ovarian function in adult rats. Experientia 35, 562-563.

Hain, A.M. (1935) The effect (a) of litter size on growth and (b) of oestrone administered during lactation (rat). $Q$. Jl exp. Physiol. 25, 303-313.

Holzhausen, C.E. (1982) Effects of medroxyprogesterone acetate administration to female neonatal rats on some physical parameters and on the ovarian cycle. Abst. Proc. Europ. Soc. Comp. Physiol. Biochem, Bielefeld, p. 194.

Holzhausen, C., Murphy, S. \& Birke, L.I.A. (1984) Neonatal exposure to a progestin via milk alters subsequent LH cyclicity in the female rat. $J$. Endocr. 100, $149-154$.

Hull, E.M. (1981) Effects of neonatal exposure to progesterone on sexual behavior of male and female rats. Physiol. Behav. 26, 401-405.

Hull, E.M., Franz, J.R., Snyder, A.M. \& Nishita, J.K. (1980) Perinatal progesterone and learning, social and reproductive behavior in rats. Physiol. Behav. 24, $251-256$.

Kato, J. \& Onouchi, T. (1981) Progesterone receptors in the cerebral cortex of neonatal female rats. Dev. Neurosci. 4, 427-432.
Kincl, R.A. \& Maqueo, M. (1965) Prevention of steroidinduced sterility in neonatal male and female rats. Endocrinology 77, 859-862.

Logothetopoulos, J., Sharma, B.B. \& Kraicer, J. (1961) Effects produced in rats by the administration of $6 \alpha-$ methyl-17 $\alpha$-hydroxyprogesterone acetate from birth to maturity. Endocrinology 68, 417-430.

MacLusky, N.G. \& McEwan, B.S. (1980) Progestin receptors in the developing rat brain and pituitary. Brain Res. 189, 262-268.

Massa, R. \& Martini, L. (1971) Interference with the 5- $\alpha$ reductase system: a new approach for developing antiandrogens. Gynecol. Invest. 2, 253-270.

Mathews, J.H., Abrams, C.A. \& Morishima, A. (1970) Pituitary adrenal function in ten patients receiving medroxyprogesterone acetate for true precocious puberty. J. clin. Endocr. Metab. 30, 653-659.

Money, J. (1970) The therapeutic use of androgendepleting hormone. J. Sex Res. 6, 165-172.

Pasqualini, J.R. \& Nguyen, B.L. (1980) Progesterone receptors in the fetal uterus and ovary of the guinea pig: evolution during fetal development and induction and stimulation in estradiol primed animals. Endocrinology 106, 1160-1165.

Philibert, D. \& Raynaud, J.P. (1973) Progesterone binding in the immature mouse and rat uterus. Steroids 22, 89-94.

Revesz, C., Chappel, C.I. \& Gaudry, R. (1960) Masculinization of female fetuses in the rat by progestational compounds. Endocrinology 66, 140-144.

Satayasthit, N., Tankeyoon, M. \& Chaudhury, R.R. (1976) The effects of medroxyprogesterone acetate, 
administered to the lactating rat, on the subsequent growth, maturation and reproductive function of the litter. J. Reprod. Fert. 46, 411-412.

Schultz, F.M. \& Wilson, J.D. (1974) Virilization of the Wolffian duct in the rat fetus by various androgens. Endocrinology 94, 979-986.

Shapiro, B.H., Goldman, A.S., Bongiovan, A.M. \& Marino, J.M. (1976) Neonatal progesterone and feminine sexual development. Nature, Lond. 264, 795-796.

Tapanainen, J. (1979) Effect of progesterone treatment on the development and function of the neonatal rat adrenals and testes. Biol. Neonate 36, 290-297.

Received 3 November 1983 